\title{
ODONTALGIAS NÃO ODONTOGÊNICAS
}

Rayza Santiago WAPNIARZ, Aguinaldo Coelho de FARIAS, Daniel BONOTTO, Priscila BRENNER, Paulo Afonso CUNALI

A dor de dente pulpar e/ou periodontal são comumente observadas e bem resolvidas nos consultórios dentários. Entretanto, estruturas da cabeça e pescoço podem produzir dores heterotópicas sentidas nos dentes, denominadas odontalgias atípicas como: odontalgia muscular, neurovascular, cardíaca, neuropática, de mucosa nasal ou sinusal e ainda psicogênica. A dor heterotópica é de difícil diagnóstico, exigindo conhecimento da anatomofisiopatologia da dor, experiência clínica e bom senso. Alguns do indícios de que uma dor no dente não é de origem dentária são: odontalgias múltiplas e espontâneas, causa dentária local insuficiente para a dor, odontalgias estimulantes em queimação e não-pulsáteis. $O$ erro na formulação da hipótese diagnóstica pode levar o paciente a tratamentos desnecessários. Este trabalho objetiva apresentar o caso de uma paciente de 40 anos, com histórico de dor na região de pré-molares inferiores esquerdos, contínua e intensa. A dor apresentou remissão total após bloqueio anestésico do músculo esternocleidomastóideo ipsilateral, confirmando tratar-se de uma odontalgia miogênica. Em suma, as odontalgias não odontogênicas são um desafio a ser superado em termos de fisiopatologia, diagnóstico e tratamento.

Palavras-chave: Diagnóstico; Dor; Síndrome miofascial. 